\title{
FEM Numerical Simulations of the Mechanical Clinching Process of HC260Y Steel
}

\author{
Josip CUMIN, Antun STOIĆ, Miroslav DUSPARA, Ivan SAMARDŽIĆ
}

\begin{abstract}
This paper presents the results of FEM numerical simulations, of the HC260Y steelsheet mechanical clinching process. The starting tool parameters were chosen for the central composite design of experiments, in order to find out which tool parameters have the largest contribution to the sheet joint interlock. Assessment of the mathematical model, and analysis of variance (ANOVA) were performed within the design of experiments. This numerical analysis was done to find the most suitable tool geometry and tool work stresses, so that the tool sets for further experiments could be manufactured and results compared with numerical results.
\end{abstract}

Keywords: FEM; HC260Y; mechanical clinching; numerical simulation; process parameters

\section{INTRODUCTION}

The mechanical clinching process is a metal forming process used for joining of metal sheets. The most used application of this technology is for the joining process of same or dissimilar (steel / aluminium / magnesium alloy) materials in automobile chassis production. The tool consists of the punch and matrix as the main components, and based on the tool configuration the C-shaped frame is used to position and guide punch toward matrix. Such tool is shown in Fig. 1.

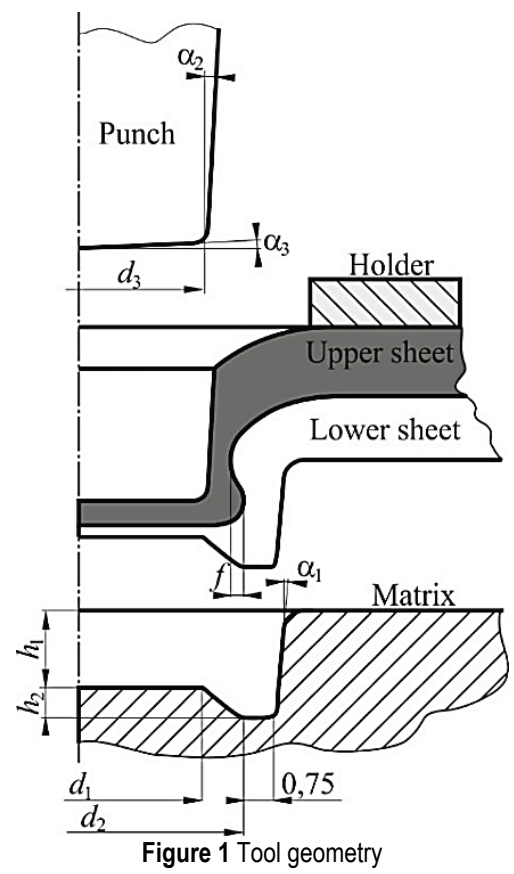

During clinching the punch presses upper sheet towards lower sheet and into the matrix cavity, therefore forcing material to plastically deform with the intention of interlock forming between two sheets in the formed joint $(f$ from Fig. 1). The goal is to produce the largest possible overlap during the mechanical clinching process.

The punch and matrix (die) can be rigid, or the matrix can have elastic rubber element whose purpose is to maintain normal force on the lower sheet. It has been determined in researches $[2,3]$ that tool geometry must be well adjusted to produce quality joint between two sheets of metal. The tool/process parameters are matrix diameters $\left(d_{1}, d_{2}\right)$, matrix height $\left(h_{1}, h_{2}\right)$, matrix and punch angles $\left(\alpha_{1}\right.$, $\alpha_{2}$ ), punch diameter $d_{3}$, different tool radii which influence material flow etc.

Since tool geometry and dimensions must be optimal to produce quality joint, often the FEM method approach is used to approximate the desired tool geometry $[2,4-6]$. Production of experimental tool sets is expensive, but with FEM approximated optimal tool geometry, only small changes on the manufactured tools might be necessary, and total cost of tool production is decreased. For the FEM input it is necessary to measure the material strain hardening curve, and to approximate test results with some of the existing strain hardening mathematical models.

The Y. Abe et al. have investigated the behavior of mechanically clinched sheet metal plates and have discovered that mechanically clinched plates have higher fatigue strength, but lower specimen tensile tearing force as opposed to the resistance welded joints [7]. The authors have also shown some of the important tool characteristics required to obtain desired geometry and interlock value $f$ in the clinched joint [7].

C. Lee et al. have investigated some of the process parameters (optimal tool geometry and dimensions) with the FEM method for the mechanical clinching of aluminium and high strength steel plates [8]. The punch/matrix clearance, type of groove shape and die depth have been varied to find which one has the highest effect on joinability. It has been found that the die groove shape and radii have the most influence on joint strength and value of interlock [8].

Benzegaou Ali et al. [9] presented paper on FEM simulation of the hybrid joining process of two dissimilar material sheets. This research included Johnson Cook damage model for the calculation of equivalent strain, which is in correlation to the neck thickness of the upper metal (Fig. 1) and has effect on joint separation.

Chao Chen et al. [10] investigated effects of two stage clinching process which consisted of regular clinching followed by compression of the clinched joint protrusion in the set of flat and bumped dies. This joint protrusion in the lower sheet is often aesthetically unsightly, and protrusion height reduction in this process has another benefit aside aesthetics which is increased joint crosstensile strength, and increased shearing strength. In the following research [11] a special rivet was placed inside previously formed joint (after clinching process), which 
was followed by clinched joint compressing process as is shown in [10].

M. Eshtayeh [12] implemented Taguchi based Grey optimization method on the 11 parameters related to the fixed clinching tool geometry. Clinching was done on dissimilar materials (Al 7075 and mild steel as stated in the paper). For the used dissimilar materials, output of this research provided optimal clinching tool geometry in terms of maximum sheet interlock, neck thickness and bottom thickness.

L. Kaščak et al. [13] investigated joining of three plates of dissimilar materials (DC06, DX53D, HP220PD) in the rigid clinching tool. It was found that the high necking of upper sheet appeared in the clinched joint. In addition, in the case of DX53D steel, the backward extrusion was observed which was proposed to be related with increased sheet thicknesses. This joining process of three sheets is considered unconventional. The same authors [14] have conducted experiments on clinching process of dual-phase DP600 steel, with clinching tool coated with CrN PVD coating. It was shown that the wear of clinching matrix is less visible than the wear on punch radius, where cracks could be observed with SEM microscope after total of 200 joints were made. Some further research was done by the same authors using different types of PVD coatings on the clinching tool [15]. The coatings were $\mathrm{ZrN}, \mathrm{CrN}, \mathrm{TiCN}$ deposited by PVD process [15]. The levels of normal stress, material flow and contact places were evaluated by FEM method [15]. It has been found that dominant wear is present in the localized radius area surrounding die cavity, which is in agreement with the authors' previous work [14].

F. Lambiase et al. [16] conducted a research on clinching possibility of reduced ductility aluminium plates. Reduced ductility is related to high strain hardening of aluminium alloys. In the applied approach the goal was to optimize tool set geometry with the intention of necking minimization, and plastic strain minimization. During clinching process sheet plates were preheated with hot air gun to improve formability [16].

Meng-han Wang et al. [17] developed shape optimization system of clinching tool based on the Bezier curve. Tool shape was described with Bezier curve (with controllable points). The initial tool shape of several known good cases was given as an input, then genetic algorithm (GA) interfaced with FEM model was utilized to solve multi-variable global optimization problem. Optimal tool geometry was obtained as result.

$\mathrm{X}$. Wang et al. [18] developed systematic and adaptive multi-objective optimization for clinching process. Modeling and optimization was done with the use of FEM method, Response Surface Method (RSM), Parameter Study (PS) and non-dominated sorting genetic algorithmII (NSGA-II). As a result of this research the significant parameters for the creation of interlock and joint fracture tensile force were determined and analyzed through multiple statistic approaches [18].

D. Ren et al. [19] proposed a novel approach of combined clinching and resistance spot welding of galvanized mild steel to 5083 aluminium alloy. The artificial neural network with back propagation algorithm was used to produce such clinching tool shape which was able to produce increased tensile strength of the joint.
W. Menghan et al. developed optimization technology, and corresponding program utilizing FEM and genetic algorithm (GA) similar to the work of [17].

Y. Abe et al. [20] presented research on clinching possibility of ultra-high strength steels. These steels have low ductility which results in high thinning of the upper sheet (necking). Sheet necking results in fracture or reduced loading capability for this type of joint. In this work [20], the preforming operation is utilized to shape lower sheet first, then upper sheet is placed over, and the joint is made by clinching tool. It was stated [20] that today most automotive panels are made from high strength steel, and they are connected by means of spot welding. Such welds have higher tensile load, but lower fatigue strength due to the initiation and propagation of cracks in the joint. On the other hand, when using clinching tools, it is necessary to use twice or more clinched joints to obtain tensile strength, but those joints are less prone to fatigue [20].

In the presented paper, the central composite DOE alongside with the FEM method was utilized to inspect the largest material strain, contact points, material flow, interlock and necking. For the optimal cases, tool forces and maximum stress points are analyzed.

For the used design of experiment, interactions between factors and their significance on the creation of interlock is shown.

Based on the obtained tool loads and taking into account safe factor, the proper tool material was selected. Tool sets (Fig. 10) are to be produced and utilized for validation of FEM results.

\section{MATERIAL}

The material used in FEM simulations was HC260Y, Interstitial Free (IF) steel with high strength and high ductility, often used in automotive industry for energy absorbing elements. Material mechanical properties were previously determined by means of uniaxial tensile test. Strain hardening curve is described with the expression:

$k_{\mathrm{f}}=673,1 \cdot \varphi^{0,21567}$

where $k_{\mathrm{f}}$ is the material flow strength and $\varphi$ natural (logarithmic) strain. The tensile test specimens were cut from $1 \mathrm{~mm}$ thick sheet, and this material thickness was used in the FEM numerical simulations.

\section{DESIGN OF EXPERIMENTS}

The central-composite design of experiments was utilized to observe interaction of tool parameters on the appearance of interlock in the sheets. Previous to DOE plan, a large number of numerical simulations were performed in order to come in the vicinity of such tool parameters where interlock could be observed.

The selected parameters are shown in Fig. 1, first is the matrix diameter $d_{1}$, second the ratio of matrix height ( $\left.h_{1} / h_{2}\right)$, and third the matrix angle $\alpha_{1}$ (shown in Fig. 2).

The matrix dimension $d_{2}$ was always set as $d_{2}=d_{1}+$ $1,5 \mathrm{~mm}$, thus enabling change of punch/matrix clearance with the change of dimension $d_{2}$. 


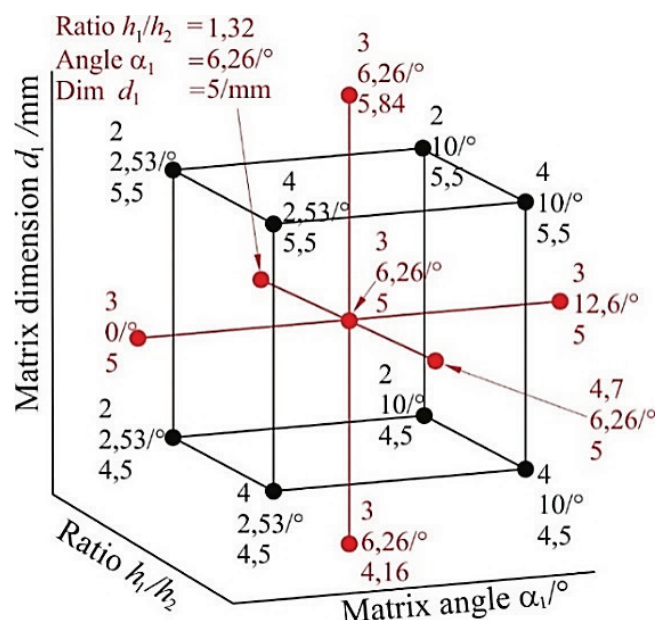

Figure 2 Clinching tool parameters from central composite DOE

Different heights of matrix were used preliminarily, but to use as many variable data as possible into account, the ratio of matrix heights $h_{1} / h_{2}$ was used instead in the DOE.

These tool heights were used as follows:

$$
\begin{aligned}
& h_{1} / h_{2}=1,6 / 0,8=2 \\
& h_{1} / h_{2}=1,6 / 0,5 \dot{3}=3 \\
& h_{1} / h_{2}=1,6 / 0,4=4 \\
& h_{1} / h_{2}=1,6 / 1,21=1,32 \\
& h_{1} / h_{2}=1,6 / 0,34=4,7
\end{aligned}
$$

The matrix angle denoted with $\alpha_{1}$ was changed from $0^{\circ}$ (lowest point) up to $12^{\circ}$ (highest point) according to central composite DOE.

It is supposed, that for degree of $\alpha_{1}=0^{\circ}$, the side effect should be harder joint removal from the matrix.

\section{FINITE ELEMENT METHOD}

The mechanical clinching process with respectful tool parameters was simulated in the FEM program MSC.MARC. The matrix, punch, sheet, and sheet holder were set as axisymmetric geometries, which is shown in Fig. 3. Both metal sheets have had thicknesses of $1 \mathrm{~mm}$, and for simulation purposes outer diameter of $20 \mathrm{~mm}$ to ensure that the ends of sheet in FEM model are long enough from the clinched joint itself. It was done for the purpose of creating computationally undemanding model, while maintaining sheet joint properties in the model.

The punch diameter was set as $d_{3}=6,5 \mathrm{~mm}$, with angle $\alpha_{2}=6^{\circ}$, angle $\alpha_{3}=5^{\circ}$, punch edge radii of $0,4 \mathrm{~mm}$ and this geometry was constant in all simulation cases, Fig. 3.

In the FEM setup, model was axisymmetrical with the use of assumed strain and constant dilatation functions, which are to be used in the large strain deformation cases along with the lower order quadrilateral elements, to avoid possible problems with element locking due to overconstraints for nearly incompressible behavior [21]. The sheets were meshed with the lower order quadrilateral elements type 10 [21], with the size of $0,08 \times 0,08 \mathrm{~mm}$. Subsequent fine remeshing with the element edge length goal size of $0,05 \mathrm{~mm}$ was used with the "Advancing front quad" internal mesher, which was activated when logarithmic strain was larger than $\varphi=0,15$, and when the quadrilateral element was distorted (internal angle larger than $120^{\circ}$ ).

The numerical simulation was set as large strain plasticity with large strain updated Lagrange option, where additive decomposition method was used for matrix solving.

Contact control was done internally through the software with CTABLE option, where it was necessary to define possible deformable contact bodies (two sheets), and rigid bodies with prescribed motion (matrix was set as stationary, and punch had linear z-axis motion). Also, the contact boundary was set to be described in analytical way instead of geometrical by checking appropriate functions and selecting contacting nodes on both sheet metal meshes. Friction factor of $\mu=0,15$ was assumed in all simulations with reference to the work [2], since in simulation models where the results should be compared it is more important that the same contact and friction conditions are used in all simulation cases.

Coulomb friction model, with bilinear contact control numerical model [21] approach was used.

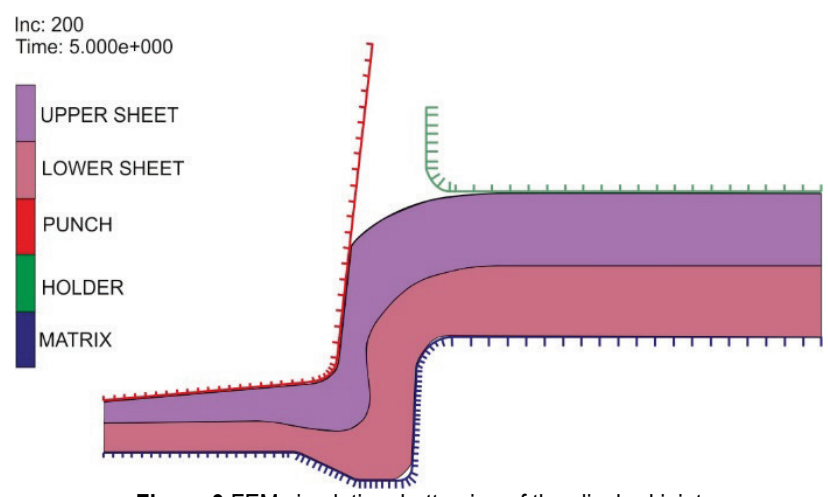

Figure 3 FEM simulation, bottoming of the clinched joint

\section{RESULTS}

The results form numerical simulations and DOE are shown in Tab. 1. For the good joint quality, largest interlock $f$ (from Fig. 1) is desired. At the same time, it is good assumption that low thickness of the upper plate is not desirable due to the possible sheet fracture (necking). In Tab. 1 , three factors are shown, matrix diameter $d_{1}$ (mm), ratio of matrix depth $h_{1} / h_{2}$, and matrix wall angle $\alpha_{1}$ ${ }^{\circ}$ ). Punch tool force in $\mathrm{kN}$ is later used for stress analysis, tool construction and material choice.

Table 1 Results from FEM experiments

\begin{tabular}{|c|c|c|c|c|c|}
\hline No. & $d_{1} / \mathrm{mm}$ & Ration $h_{1} / h_{2}$ & $\alpha_{1} /{ }^{\circ}$ & Interlock $f / \mathrm{mm}$ & $F / \mathrm{kN}$ \\
\hline 1 & 5 & 1,32 & 6,26 & 0,022 & 86,18 \\
\hline 2 & 5 & 3 & 12,6 & 0,005 & 96,92 \\
\hline 3 & 5,5 & 2 & 10 & 0,0178 & 70,72 \\
\hline 4 & 4,5 & 4 & 2,53 & 0,008 & 118,6 \\
\hline 5 & 4,5 & 2 & 10 & 0,0185 & 130,2 \\
\hline 6 & 5 & 3 & 0 & 0,037 & 118,37 \\
\hline 7 & 5 & 3 & 6,26 & 0,0196 & 100,08 \\
\hline 8 & 5,84 & 3 & 6,26 & 0,055 & 110,25 \\
\hline 9 & 5 & 4,68 & 6,26 & 0,0196 & 98,13 \\
\hline 10 & 5,5 & 4 & 10 & 0,0257 & 85,09 \\
\hline 11 & 4,5 & 2 & 2,53 & 0,022 & 132,5 \\
\hline 12 & 5,5 & 4 & 2,53 & 0,029 & 78,98 \\
\hline 13 & 5,5 & 2 & 2,53 & 0,07 & 127,4 \\
\hline 14 & 4,5 & 4 & 10 & 0,0184 & 123,3 \\
\hline 15 & 4,16 & 3 & 6,26 & 0,012 & 134,92 \\
\hline
\end{tabular}


Tab. 2 shows ANOVA for the two-factor interaction model. The proposed mathematical model has $F$-value of 9,43 and from the statistic tables it can be seen that for $95 \%$ confidence, the $F$-value should be at least $F=3,581$. This proves that the mathematical model is correct with $95 \%$ confidence.

As for the factors and their interactions from Tab. 2, Factor $A$ has the $F$-value $F=25,49$ which is also larger than limit of $F=5,318$ for the factor to be significant in the mathematical model with $95 \%$ confidence. Factor $B$ has $F$ $=2,68$ which is lower than $F=5,318$ thus implying that factor $B$ is not significant for the interlock.

Table 2 ANOVA

\begin{tabular}{|l|c|c|c|c|c|}
\hline \multicolumn{1}{|c|}{ Source } & $\begin{array}{c}\text { Sum of } \\
\text { squares }\end{array}$ & $d f$ & $\begin{array}{c}\text { Mean } \\
\text { square }\end{array}$ & $\begin{array}{c}F \text { - } \\
\text { value }\end{array}$ & $\begin{array}{c}p \text {-value } \\
\text { Prob }>F\end{array}$ \\
\hline Model & $3,676 \mathrm{E}-003$ & 6 & $6,127 \mathrm{E}-004$ & 9,43 & 0,0029 \\
\hline Fact. $A d_{1} / \mathrm{mm}$ & $1,657 \mathrm{E}-003$ & 1 & $1,657 \mathrm{E}-003$ & 25,49 & 0,0010 \\
\hline Fact. $B$ ratio $h_{1} / h_{2}$ & $1,739 \mathrm{E}-004$ & 1 & $1,739 \mathrm{E}-004$ & 2,68 & 0,1405 \\
\hline Fact. $C \alpha_{1} /{ }^{\circ}$ & $8,060 \mathrm{E}-004$ & 1 & $8,060 \mathrm{E}-004$ & 12,40 & 0,00078 \\
\hline Inter. $A B$ & $5,778 \mathrm{E}-005$ & 1 & $5,778 \mathrm{E}-005$ & 0,89 & 0,3734 \\
\hline Inter. $A C$ & $4,485 \mathrm{E}-004$ & 1 & $4,485 \mathrm{E}-004$ & 6,90 & 0,0303 \\
\hline Inter. $B C$ & $5,330 \mathrm{E}-004$ & 1 & $5,330 \mathrm{E}-004$ & 8,20 & 0,0210 \\
\hline Resid. & $5,200 \mathrm{E}-004$ & 8 & $6,500 \mathrm{E}-005$ & & \\
\hline Cor Total & $4,196 \mathrm{E}-003$ & 14 & & & \\
\hline
\end{tabular}

Factor $C$ has the $F$-value $F=12,4$ which is larger than the fringe limit $F=11,259$ for the $99 \%$ model confidence, or $F=5,318$ for the $95 \%$ confidence, so it can be said that the factor $C$ has the highest influence on the amount of interlock in the mechanically clinched joint from numerical experiments. For the factor interaction $A C$, it can be said that it is also significant for the mathematical model, since $p<0,005$.

The proposed mathematical model is

$$
\begin{aligned}
& f=-0,22655+0,063272 \cdot d_{1}+\left(\frac{h_{1}}{h_{2}}\right) \cdot 9,61478 \mathrm{E}-03+ \\
& +0,011434 \cdot \alpha_{1}-\left(d_{1} \cdot \frac{h_{1}}{h_{2}}\right) \cdot 5,375 \mathrm{E}-03- \\
& -\left(d_{1} \cdot \alpha_{1}\right) \cdot 4,00937 \mathrm{E}-03+\left(\frac{h_{1}}{h_{2}} \cdot \alpha_{1}\right) \cdot 2,18541 \mathrm{E}-04(\mathrm{~mm})
\end{aligned}
$$

Fig. 4 shows interaction of factors $A$, and $B$ on the amount of interlock $f$ from Fig. 1. It can be observed that from the median value of factor $C$, interlock $f$ is largest when the ratio of matrix dimensions $h_{1} / h_{2}$ is lower, and with the larger diameter of matrix $d_{1}$.

Fig. 5 shows interactions of factors $A, C$, for the median value of factor $B$. It can be observed that interlock $f$ is the largest when the angle $\alpha_{1}$ is the smallest and diameter $d_{1}$ the largest. Fig. 6 shows interactions of factors $B, C$, on the value of interlock $f$. It can be seen that the value of interlock is highest when the height ratio $h_{1} / h_{2}$ is lowest, while ratio of matrix angle $\alpha_{1}$ is at the lowest value. Fig. 7 shows normal probability vs. internally studentised residuals of the proposed mathematical model (3). Therefore, the coefficient of determination of expression (3) is $R^{2}=0,8761$.

Based on the obtained data from Tab. 1, states No. 11, No. 13, and No. 15 were further FEM analyzed with respect to stresses occurring in the punching tool. As was mentioned earlier, the purpose of this paper is to obtain forces, pressures and stresses on clinching tool, to construct tool, and to select appropriate material for the tool.

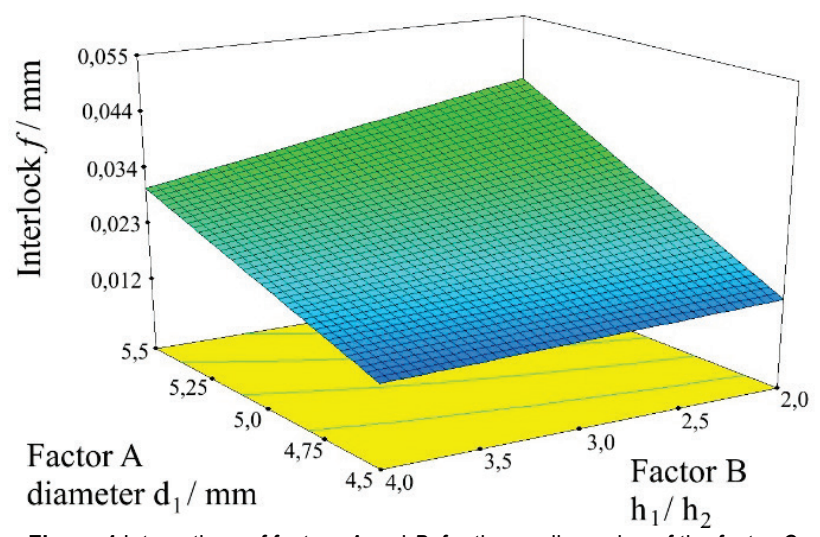

Figure 4 Interactions of factors $A$ and $B$, for the median value of the factor $C$

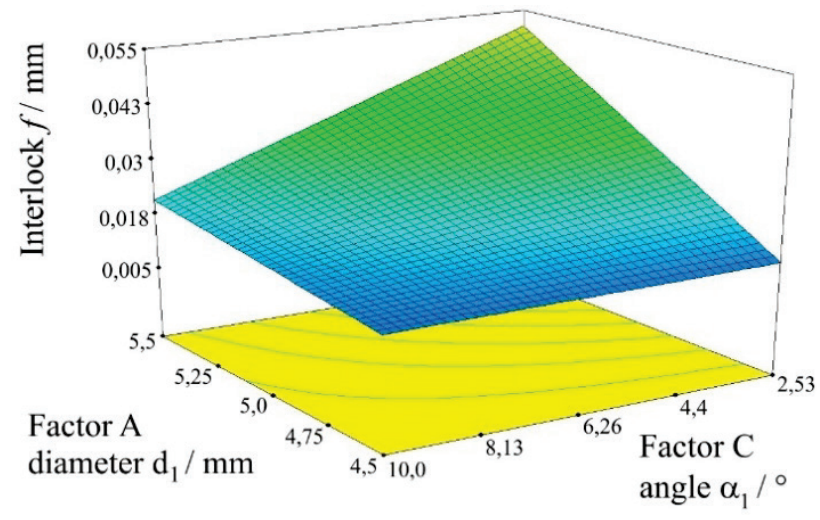

Figure 5 Interactions of factors $A$ and $C$, for the median value of the factor $B$

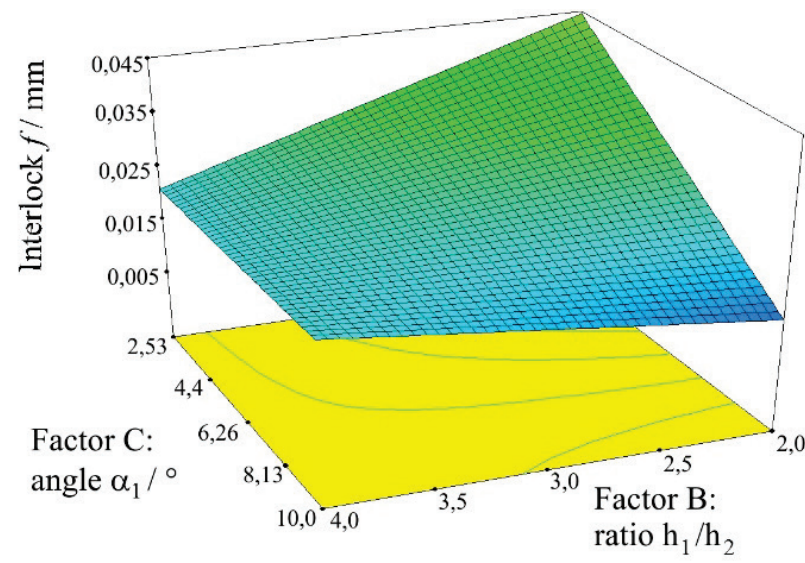

Figure 6 Interactions of factors $B$ and $C$, for the median value of the factor $A$

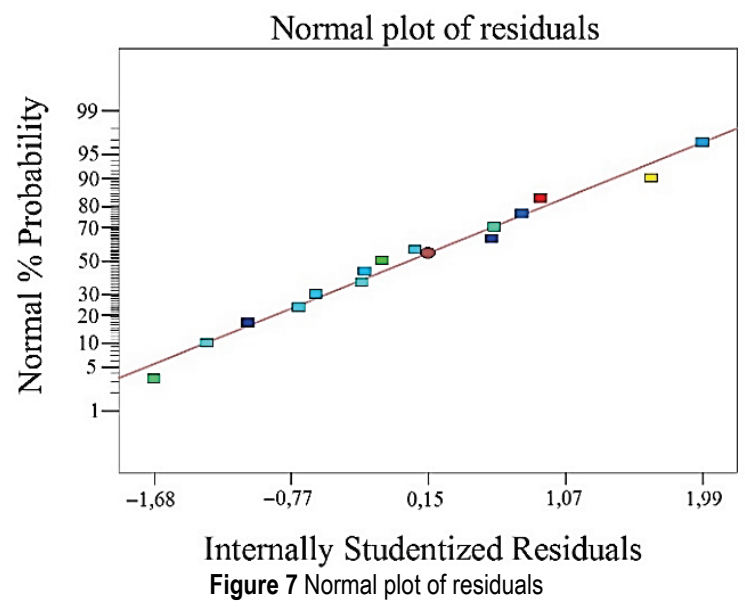




\section{TOOL FORCES AND STRESSES}

With respect to the highest punch forces seen in table 1 , the three cases were further analyzed. Of particular interest are cases No. 11 and No. 15 from Tab. 1, since they have highest force on the tool components, and No. 13 since it has very similar force magnitude as cases 11 and 15 , but with the highest observable interlock.

This time, the punch was not modelled as rigid body with prescribed movement, but instead it was modelled as deformable body with axisymmetric property as the rest of the model has been set.

Several mesh sizes were tested for the convergence of results and necessary CPU time. Tab. 2 shows comparison of testing different desired mesh element sizes and CPU times.

Table 3 Different mesh sizes

\begin{tabular}{|c|c|c|c|}
\hline No. & Mesh size/ mm & Max. punch stress / MPa & CPU time \\
\hline 1 & 0,35 & 3182 & 1174 \\
\hline 2 & 0,20 & 3167 & 1590 \\
\hline 3 & 0,15 & 3160 & 1886 \\
\hline 4 & 0,10 & 3159 & 2076 \\
\hline 5 & 0,05 & 3159 & 5492 \\
\hline
\end{tabular}

The punch itself was chosen to be meshed with desired element mesh size of $0,1 \mathrm{~mm}$. From Tab. 3 , it can be seen that the desired element size gives good approximation of the results, with moderate CPU time, and punch mesh is of comparable size with the sheet metal mesh size. Punch was described with the set of curves which had attached curve divisions from which Quadrilateral Advanced Front planar mesher was called to create quadrilateral mesh.

Both Punch mesh and sheet metal mesh have had axisymmetrical properties set. The punch material was set only as elastic with elastic modulus $E=210 \mathrm{GPa}$ and Poisson's ratio of $v=0,3$ as it is supposed that the punching tool will deform only elastically during clinching process.

Contacts were set through option CTABLE where punch elements were set as deformable, boundary nodes were selected to be analytically described during simulation. Boundary nodes of both sheets were also set to be analytically described during contact. Distance tolerance was set to $0,005 \mathrm{~mm}$ and tolerance bias factor to 0,95 . Contact was solved with option of "bilinear contact control" with optimized contact control equations.

The sheet material HC260Y was described as elasticplastic with multi linear isotropic hardening law, and plastic strain hardening flow curve was determined previously.

Boundary conditions were set as axisymmetric on the symmetry nodes of both sheets, then separately for punch symmetry nodes. Punch upper nodes had boundary conditions that prevented movement in the symmetry axis dimension, and movement was set through table input on the rigid bodies of matrix and sheet holder. In such a way, the total forces and stresses on the punch could be obtained.

Fig. 8 shows the resulting internal von Mises equivalent stress in the punching tool for the No. 11 case from Tab. 1.

Fig. 9 shows enlarged part of the punch from Fig. 8 (case No. 11 from Tab. 1). The place of the maximum compressive stress $\sigma=3159 \mathrm{MPa}$ is seen in the punch. The punch force in this case is $F=132,5 \mathrm{kN}$ as seen in Tab. 1 .

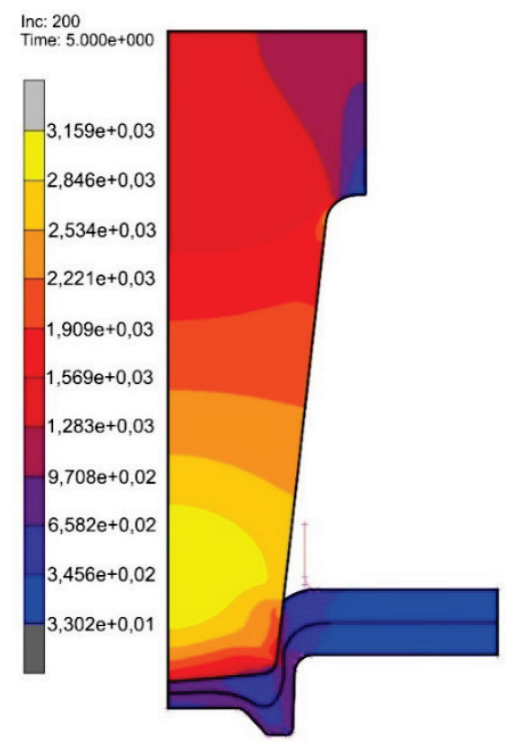

Figure 8 Von Mises stress in the punching tool for state No. 11

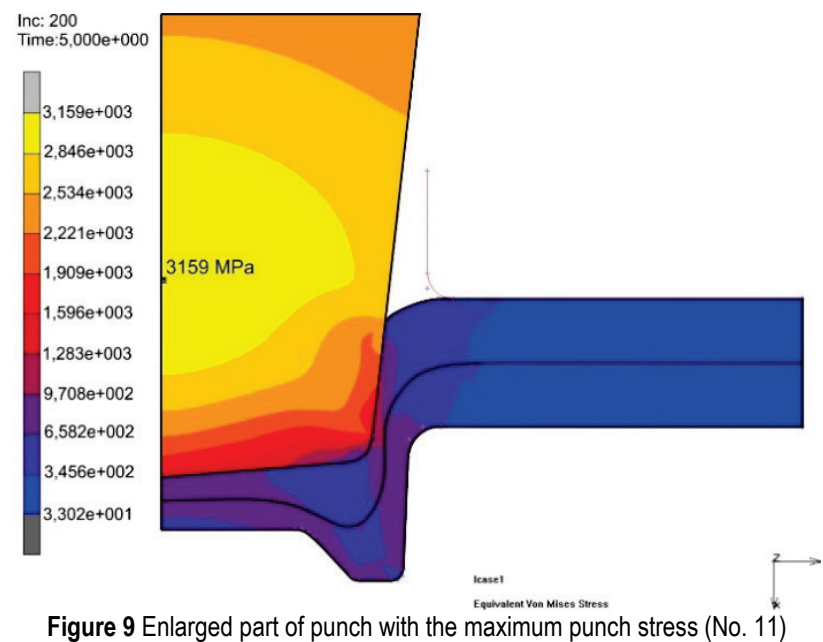

Fig. 10 shows place of maximum compressive stress of $\sigma=3290 \mathrm{MPa}$, for the punch force of $F=134,92 \mathrm{kN}$ as seen in Tab. 1 (No. 15 case).

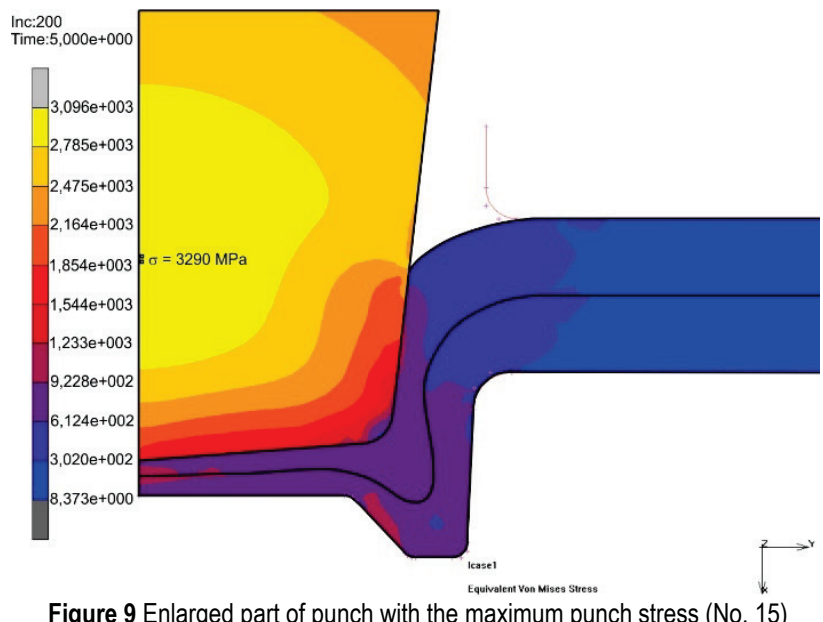

Figure 9 Enlarged part of punch with the maximum punch stress (No. 15)

Considering the stress amount in the punch material, it was decided that the punch material should be most often used punch steel EN 1.2379 / X153CrMoV12, since it has transverse rupture pressure of $3500 \mathrm{MPa}[22,23]$. This 
material is also known as D2 steel which can be heat treated to 60-63 HRC. This hardness is desirable for the purpose of clinching tool, since it has excellent wear resistance and small tool deformation.

The material for the matrix is also selected as $\mathrm{X} 153 \mathrm{CrMoV} 12$ steel in order to reduce material costs. Both punch/matrix sets for the experiments are to be made of solid X153CrMoV12 steel bar, machined and heat treated by quenching from $1000-1050{ }^{\circ} \mathrm{C}$, and subsequently tempered at $150-200{ }^{\circ} \mathrm{C}$ [23] to achieve optimal hardness.

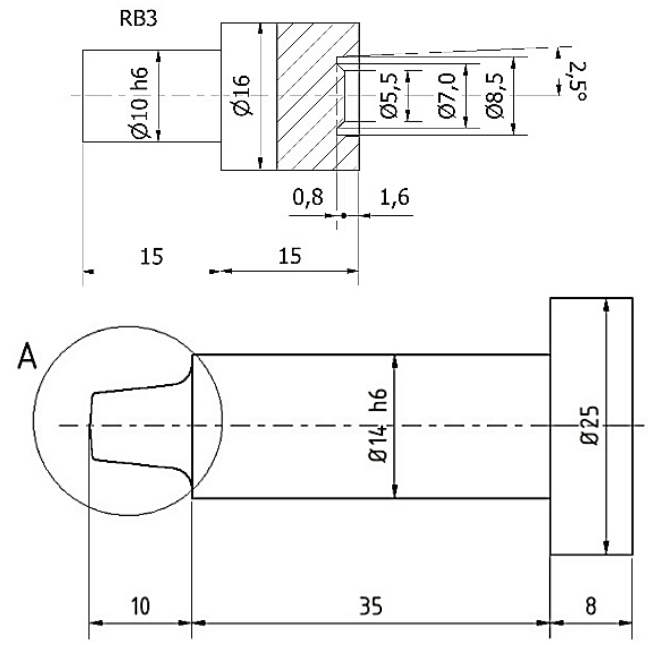

A $(4: 1)$

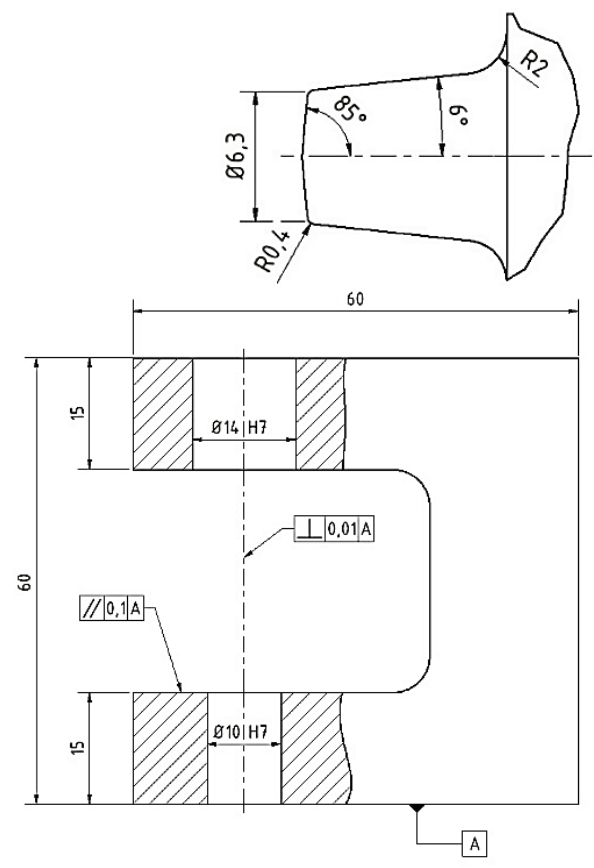

Figure 10 Clinching tool

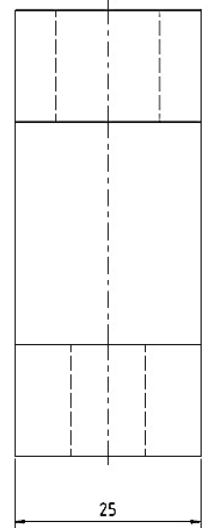

Fig. 10 shows clinching tool dimensions, which is to be produced and tested on $\mathrm{HC} 260 \mathrm{Y}$ sheet stripes to verify FEM model. There is a plan to test AlMg3 and AlMg5 material clinching possibility with this tool or its modified parts, as well as clinching possibility of $\mathrm{HC} 260 \mathrm{Y}$ sheets with $\mathrm{AlMg} 3 / \mathrm{AlMg} 5$ sheets.

\section{CONCLUSION}

In this paper, the clinching tool dimensions were used as parameters for the central composite design of experiments.

Based on the obtained points in the design of experiments, the FEM simulations were performed. From FEM results the clinching tool loads were obtained alongside with the insight of how interlock is formed due to the material flow governed by the tool shape.

It has been observed that for the used material properties and tool configuration, the largest influence on interlock comes from the largest matrix diameter $d_{1}$, and smaller matrix values $\alpha_{1}$

For the good joint quality, the upper sheet neck thickness should be chosen largest while the interlock is maximal. Through numerical FEM simulations it was observed that besides varied tool parameters (and with the constant other process parameters like loading speed, friction, contact options etc.), the largest influence on sheet interlock is obtained through matrix diameter $d_{1}$, matrix angle $\alpha_{1}$, interaction of interaction of $d_{1}$ and $\alpha_{1}$, interaction of $h_{1} / h_{2}$ and $\alpha_{1}$.

Based on the tool forces and stresses, the EN 1.2379/ $\mathrm{X} 153 \mathrm{CrMoV} 12$ / (D2) steel was chosen as optimal material for the production of test punch/matrix. If D2 steel should not be available, the next optimal tool steel that could be used for loading conditions is EN 1.3343 / HS-6-5-2 [22].

In further research, the above mentioned tool configurations (Fig. 10) will be produced to validate FEM results with the laboratory experiment results. Also the plan of the future research is to examine how punch and matrix angles $\alpha_{1}, \alpha_{2}, \alpha_{3}$ affect creation of sheet interlock, with and without the following process of sheet protrusion compression, with respect to work of [10].

With machined tool sets, the plan is to further investigate similar materials such as AlMg3/AlMg5, and dissimilar such as $\mathrm{Al} /$ steel sheet clinching possibilities.

\section{REFERENCES}

[1] Abe, Y., Mori, K., \& Kato, T. (2012). Joining of high strength steel and aluminium alloy sheets by mechanical clinching with dies for control of metal flow. J Mater ProcTechnol, 212(4), 884-889. https://doi.org/10.1016/j.jmatprotec.2011.11.015

[2] Lambiase, F. (2013). Influence of process parameters in mechanical clinching with extensible dies. International journal of advanced manufacturing technologies, 66(9), 2123-2131. https://doi.org/10.1007/s00170-012-4486-4

[3] Mucha, J., Kaščak, L., \& Spišak, E. (2011). Joining the car body sheets using clinching process with various thicknesses and mechanical property arangements. Archives of civil and mechanical engineering, 6(1), 135-148. https://doi.org/10.1016/S1644-9665(12)60179-4

[4] Deng, W. J., Zhang, J. Y., Liu, L. W., He, D., \& Xia, W. (2017). Simulation Analysis of a New Chips Recycling Process Termed Forming Extrusion Cutting. International Journal of Simulation Modelling, 16(4), 694-706. https://doi.org/10.2507/IJSIMM16(4)C016

[5] Volk, M., Nardin, B., \& Dolsak, B. (2014). Determining the optimal area-dependent blank holder forces in deep drawing using the response surface method. Advances in Production Engineering \& Management, (2)9, 71-82. http://dx.doi.org/10.14743/apem2014.2.177 
[6] Dezelak, M., Stepisnik, A., Pahole, I., \& Ficko, M. (2014). Evaluation of Twist Springback Prediction after an AHSS Forming Process. International Journal of Simulation Modelling, 13(2), 171-182. https://doi.org/10.2507/IJSIMM13(2)4.261

[7] Abe, Y., Kato, T., Mori, K., \& Nishino, S. (2014) Mechanical clinching of ultra-high strength steel sheets and strength of joints. Journal of materials processing technology, 214, 2112-2118. https://doi.org/10.1016/j.jmatprotec.2014.03.003

[8] Lee, C., Kim, J., Lee, S., Ko, D., \& Kim, B. (2010). Parametric study on mechanical clinching process for joining aluminium alloy and high strength steel sheets. Journal of mechanical science and technology, 24, 123-126. https://doi.org/10.1007/s12206-009-1118-5

[9] Benzegaou, A. \& Benabderrahmane, B. (2017). Finite element simulation of the hybrid clinch joining. Int $J$ AdvManufTechnol, 89, 439-449. https://doi.org/10.1007/s00170-016-9094-2

[10] Chen, C., Han, X., Zhao, S., Xu, F., Zhao, X., \& Ishida, T. (2017). Comparative study on two compressing methods of clinched joints with dissimilar aluminum alloy sheets. Int $J$ AdvManufTechnol, 93, 1929-1937. https://doi.org/10.1007/s00170-017-0650-1

[11] Chen, C., Zhao, S., Han, X., Cui, M., \& Fan, S. (2017). Investigation of the height-reducing method for clinched joint with AL5052 and AL6061. Int J AdvManufTechnol, 89, 2269-2276. https://doi.org/10.1007/s00170-016-9266-0

[12] Eshtayeh, M. \& Hrairi, M. (2016). Multi objective optimization of clinching joints quality using Grey-based Taguchi method. Int J AdvManufTechnol, 87, 223-249. https://doi.org/10.1007/s00170-016-8471-1

[13] Kaščák, L., Spišák, E., \& Kubík, R. (2017). Finite element calculation of clinching with rigid die of three steel sheets. Strength of Materials, 49(4), 488-499. https://doi.org/10.1007/s11223-017-9892-2

[14] Kaščák, L., Spišák, E., \& Kubík, R. (2016). FEM analysis of clinching tool load in a joint of dual-phase steels. Strength of Materials, 48(4), 533-539. https://doi.org/10.1007/s11223-016-9795-7

[15] Kašćák, L., Mucha, J., \& Spišák, E. (2017). Wear study of mechanical clinching dies during joining of advanced highstrength steel sheets. Strength of Materials, 49, 726-737. https://doi.org/10.1007/s11223-017-9918-9

[16] Lambiase, F., Di Ilio, A., \& Paoletti, A. (2015). Joining aluminium alloys with reduced ductility by mechanical clinching. Int J AdvManufTechnol, 77, 1295-1304. https://doi.org/10.1007/s00170-014-6556-2

[17] Wang, M., Xiao, G., Li, Z., \& Wang, J. (2018). Shape optimization methodology of clinching tools based on Bezier curve. Int J AdvManufTechnol, 94, 2267-2280. https://doi.org/10.1007/s00170-017-0987-5

[18] Wang, X., Li, X., Shen, Z., Ma, Y., \& Liu, H. (2018). Finite element simulation on investigations, modeling, and multiobjective optimization for clinch joining process design accounting for process parameters and design constraints. The International Journal of Advanced Manufacturing Technology, 96, 3481-3501. https://doi.org/10.1007/s00170-018-1708-4

[19] Ren, D., Zhao, D., Liu, L., \& Zhao, K. (2018). Clinchresistance spot welding of galvanized mild steel to $5083 \mathrm{Al}$ alloy. The International Journal of Advanced Manufacturing Technology, (online). https://doi.org/10.1007/s00170-018-2854-4

[20] Abe, Y., Ishihata, S., Maeda, T., \& Mori, K. (2018). Mechanical clinching process using preforming of lower sheet for improvement of joinability. $17^{\text {th }}$ International Conference on Metal Forming, Metal Forming / Japan, 1360-1367. https://doi.org/10.1016/j.promfg.2018.07.347
[21] MSC Software. (2007). Volume B: Element library, MSC Software, U.S.A.

[22] AJACS/Mitsumi product data file. Characteristics of punching tools. Ajacs die sales, http://www.ajacs.com/ metal-forming-catalog/misumi/369-pg1078-1109-productdata/file (3.4.2017)

[23] Steel grades // X153CrMoV12 steel, http://www.steelgrades.com/Steel-Grades/Tool-Steel-Hard-Alloy/ x153crmov12.html (3.4.2017)

Contact information:

Josip CUMIN, dr. sc.

J. J. Strossmayer University of Osijek,

Mechanical Engineering Faculty in Slavonski Brod

Trg Ivane Brlić-Mažuranić 2, 35000 Slavonski Brod, Croatia

E-mail: jcumin@sfsb.hr

Antun STOIĆ, prof. dr. sC.

J. J. Strossmayer University of Osijek,

Mechanical Engineering Faculty in Slavonski Brod

Trg Ivane Brlić-Mažuranić 2, 35000 Slavonski Brod, Croatia

E-mail: antun.stoic@sfsb.hr

Miroslav DUSPARA, doc. dr. sc

J. J. Strossmayer University of Osijek,

Mechanical Engineering Faculty in Slavonski Brod

Trg Ivane Brlić-Mažuranić 2, 35000 Slavonski Brod, Croatia

E-mail: miroslav.duspara@sfsb.hr

Ivan SAMARDŽlć, prof. dr. sc.

J. J. Strossmayer University of Osijek,

Mechanical Engineering Faculty in Slavonski Brod

Trg Ivane Brlić-Mažuranić 2, 35000 Slavonski Brod, Croatia

E-mail: ivan.samardzic@sfsb.hr 